\title{
Negative correlations between larval and juvenile growth rates in winter flounder: implications of compensatory growth for variation in size-at-age*
}

\author{
D. F. Bertram, R. C. Chambers**, W. C. Leggett \\ Department of Biology, McGill University, 1205 Ave. Dr. Penfield, Montreal, Québec, Canada H3A 1B1
}

\begin{abstract}
We address the hypothesis that fish that grow rapidly as larvae also grow rapidly as juveniles. Winter flounder Pleuronectes americanus were reared from hatching through the larval period and up to $2 \mathrm{mo}$ into the juvenile period. Successive cohorts of fish which metamorphosed on the same day were pooled and measured at weekly intervals during the early juvenile period. Growth rates of larvae and juveniles were inversely related. This resulted in compensation in size-at-age by juveniles that grew relatively slowly as larvae. Although the complete analysis of juvenile growth rates was confined to Weeks 1 to 4 following metamorphosis, an analysis of early metamorphosed cohorts for which 3 additional weeks of measurements were available revealed that juvenile growth rates exhibited during Weeks 1 to 4 were maintained during Weeks 5 to 7 . Among these early metamorphosed cohorts there was evidence that size-at-age converged during Weeks 1 to 7 of the juvenile period. Our results suggest that size advantages gained during the larval period can be lost in the early juvenile period. This is important because size- and growth-dependent processes are known to directly affect survival and reproduction. If growth compensation is general, future studies which examine the consequences of size-dependent phenomena during the larval and juvenile periods of fishes will need to integrate the dynamics of growth in both periods rather than considering them in isolation.
\end{abstract}

\section{INTRODUCTION}

In marine fishes, fast-growing larvae are larger-atage, develop more quickly, spend less time in periods or sizes of high vulnerability to predation, and are generally believed to suffer lower mortality (e.g. Chambers \& Leggett 1987, Houde 1987). Despite the interest in, and potential importance of, variability in larval growth on population dynamics, few studies have yet experimentally evaluated the survival consequences of growth rate variation in fish (but see Rosenberg \& Haugen 1982). Many studies have examined predation risk in relation to larval size in fishes (e.g. Bailey \& Batty 1984, Brownell 1985, Folkvord \& Hunter 1986, Pepin et

- Contribution to the programs of GIROQ (Groupe interuniversitaire de recherches oceanographiques du Québec) and the Huntsman Marine Science Centre

- Present address: Huntsman Marine Science Centre, Brandy Cove Rd, St. Andrews, New Brunswick, Canada EOG $2 \times 0$ al. 1987, 1992, Miller et al. 1988, Fuiman 1989, Litvak \& Leggett 1992) but these studies, with the exception of those by Litvak \& Leggett (1992) and Pepin et al. (1992), have typically confounded size and age and none has examined growth rate per se.

A knowledge of covariance in growth rates of individuals during different early life history periods is vital if growth rates are to be used to forecast survival potential. For example, if fish which grow rapidly as larvae continue to grow rapidly as juveniles, they will experience either a survival advantage or a disadvantage, depending upon whether growth rate or size-atage is positively or negatively related to mortality. Limited evidence suggests that rapid growth may be advantageous in larval fish (e.g. Rosenberg \& Haugen 1982) and several studies report benefits for large size among juveniles. For example, in some species winterkill is inversely related to size of juveniles during their first winter (e.g. Henderson et al. 1988, Johnson \& Evans 1990). It is also possible that fast-growing individuals mature earlier, or exhibit larger size and higher 
fecundity at reproduction (e.g. Smith 1987. Travis et al. 1987, Semlitsch et al. 1988)

In fishes the term 'size hierarchy' (Brown 1946, 1957. Blaxter 1969, 1988) has been used to describe patterns of increased variation in size with age within a cohort. This term implies positive covariance in size-at-age, and serves to reinforce the notion of progressive divergence of individual growth trajectories. In mesocosm experiments with turbot larvae Scopthalmus maximus, Rosenberg \& Haugen (1982) found that growth trajectories were linear and divergent within the first $10 \mathrm{~d}$ post-hatch. Consequently, larvae which were larger at early ages maintained their size advantages. Chambers \& Leggett (1987) summarized the limited evidence of covariation in larval and juvenile size-at-age currently available for a variety of marine taxa. Their study indicated that larvae with high growth rates exhibited larger size-at-age as juveniles. In a more recent study using laboratory-reared winter flounder Pleuronectes americanus, Chambers et al. (1988) argued that size advantages gained by fast growth during the larval period were perpetuated into the early juvenile period. Their results also suggested that slower-growing larvae grew faster as juveniles, thus compensating to some degree for their slower growth as larvae (Chambers et al. 1988). A more robust analysis of the relationship between larval and juvenile growth rates is necessary because the concept of growth compensation counters the idea that growth trajectories established in the larval period are maintained throughout ontogeny in marine fishes.

Four features limit the strength of the conclusions on juvenile growth reached by Chambers et al. (1988): sample sizes were small; juveniles were drawn from a single family: growth was followed for only $10 \mathrm{~d}$ postmetamorphosis; and the study sampled individuals from only the first third of the $35+d$ interval during which metamorphosis can occur.

In this paper we extend the analysis of the relationship between larval and juvenile growth rates in winter flounder in order to address the above limitations, and to determine whether fish which exhibit rapid growth as larvae continue to do so as juveniles. Two processes that could account for the observed growth patterns are outlined. Finally, we discuss the interpretation and possible implications of the observed phenotypic variability in growth rates in terms of sizedependent survival.

\section{METHODS}

We chose winter flounder for this study because: (1) it facilitates direct comparison with the findings of previous work on this species (Chambers \& Leggett
1987, Chambers et al. 1988); and (2) flatfish are useful model organisms for the study of period-related early life history phenomena because they exhibit a rapid, distinct, and easily scored metamorphosis which clearly separates the larval and the juvenile periods.

Winter flounder were reared from fertilization through metamorphosis and up to $8 \mathrm{wk}$ into the juvenile period at the Huntsman Marine Science Centre, St. Andrews, New Brunswick, Canada. Unless otherwise stated, larval rearing followed the protocol reported by Chambers \& Leggett (1987). Eggs from 1 female and sperm from 2 males were crossed to produce 2 maternal half-sib families. The integrity of the families was maintained throughout the rearing period. Eggs were incubated at $8.5^{\circ} \mathrm{C}$ (range 7.8 to 9.2). Larvae were transferred into 25 aquaria of 38 I each and reared under static conditions. Rearing temperature was $8.8^{\circ} \mathrm{C} \pm 0.37(\mathrm{SD})$, maintained by positioning aquaria in constant-temperature water baths. Lighting followed a 16:8 day:night cycle. Rotifers were added to the aquaria $\left(5 \mathrm{ml}^{-1} \mathrm{~d}^{-1}\right)$ for $10 \mathrm{wk}$. Rotifers were cultured on a mixture of algae consisting of approximately equal quantities of Chaetoceros sp., Dunailiella sp., Isochrysis sp., and Platymonas sp. During Week 8, daily additions of $1 \mathrm{~d}$ old, algae-enriched Artemia nauplii were offered at densities of $0.25 \mathrm{ml}^{-1}$. Algae-enriched Artemia nauplii were used exclusively as food after Week 10. Care was taken to ensure that the protocol used to rear rotifers and brine shrimp was rigorously maintained and that the rearing temperature did not vary over time. These variables, and the quality of the food provided, were therefore assumed to be constant throughout the experiment.

Larvae began to settle on the bottom of the aquaria at $50 \mathrm{~d}$ post-hatch. Aquaria were inspected daily for evidence of metamorphosis of larvae to juveniles. Fish were operationally defined as juveniles when the left eye had migrated halfway over the mid-line (Stage $\mathrm{H}$ of Seikai et al. 1986). Fish which metamorphosed on the same day were measured, transferred to a circular, black, $7 \mathrm{l}$ container held at $8^{\circ} \mathrm{C}$ and maintained as a discrete cohort. The creation of these cohorts $(n=1$ to $6 ;$ mean $=4.8$ for Family 1 and 5.5 for Family 2) was repeated at intervals of 2 to $5 \mathrm{~d}$ until all fish had metamorphosed.

At the end of the study the juvenile cohorts ranged in age from 4 to 8 wk post-metamorphosis. The standard lengths of all fish in each cohort were measured weekly at $6 \times$ magnification with a dissecting microscope equipped with an eyepiece micrometer. All cohorts were measured at least 4 times following metamorphosis. The cohorts which metamorphosed earliest were measured for up to 8 consecutive weeks. Water was changed weekly and was aerated beginning at 2 wk. 
As previously noted, juveniles held in separate rearing containers were treated as separate cohorts. The identity of individuals within a cohort was not determined. Growth rates ( $\mathrm{mm} \mathrm{d}^{-1}$ ) of juveniles were established for each cohort by a least-squares fit between mean sizes-at-age from weekly measurements and age. The process of notochord flexion before and during metamorphosis made standard length an unreliable measure of size upon entering the juvenile period. Therefore, for our analysis we used juvenile sizes commencing 1 wk after metamorphosis. The extent of our size records varied with ages at metamorphosis (from 4 to $8 \mathrm{wk}$ for the last and first cohorts to metamorphose, respectively). We restricted our overall analysis of juvenile growth to Weeks 1 through 4 in order to evaluate growth records over a comparable period. Although individuals within each cohort were measured repeatedly, this procedure was used to provide a single observation for each cohort of juveniles, i.e. the average growth rate. These average growth rates were used in the statistical analyses.

Growth rates ( $\mathrm{mm} \mathrm{d}^{-1}$ ) of larvae were estimated for each cohort as the difference between mean length at metamorphosis and mean size at hatching, divided by the number of days between the 2 events. Mean size at hatching was determined separately for each of the 2 half-sib families.

Juvenile growth rates were evaluated for relationships with (1) age at metamorphosis and (2) larval growth rates by means of correlation and regression analyses. Additionally, potential effects of density of juveniles per cohort on juvenile growth rates were evaluated by treating density as a covariate. For the earliest cohorts of fish to metamorphose we evaluated whether weekly growth increments remained constant during Weeks 1 to 7 of the juvenile period using a single-sample profile analysis of 7 cohorts of early metamorphosed fish (Morrison 1976). Analyses were conducted using SYSTAT (Wilkinson 1990).

\section{RESULTS}

Size at hatching differed significantly between Families 1 and $2(2.71 \mathrm{~mm} \pm 0.12, \mathrm{n}=30$ vs $2.51 \mathrm{~mm} \pm 0.1$, $\mathrm{n}=30 ; t=7.02, \mathrm{df}=58, \mathrm{p}<0.001$ ). Length at metamorphosis also differed significantly between Families 1 and $2(7.0 \pm 0.36, \mathrm{n}=38$ vs $6.8 \pm 0.26, \mathrm{n}=162 ; t=4.98$, $\mathrm{df}=203, \mathrm{p}<0.0001)$. Length at metamorphosis did not vary with age at metamorphosis in Family 1 but showed a slight but statistically significant decrease with age at metamorphosis in Family $2(r=-0.205, \mathrm{df}=$ $160, p=0.009$ )

Juvenile growth rate ranged from 0.1 to $0.19 \mathrm{~mm} \mathrm{~d}^{-1}$ Fish grew roughly $3 \times$ faster as juveniles than as larvae.

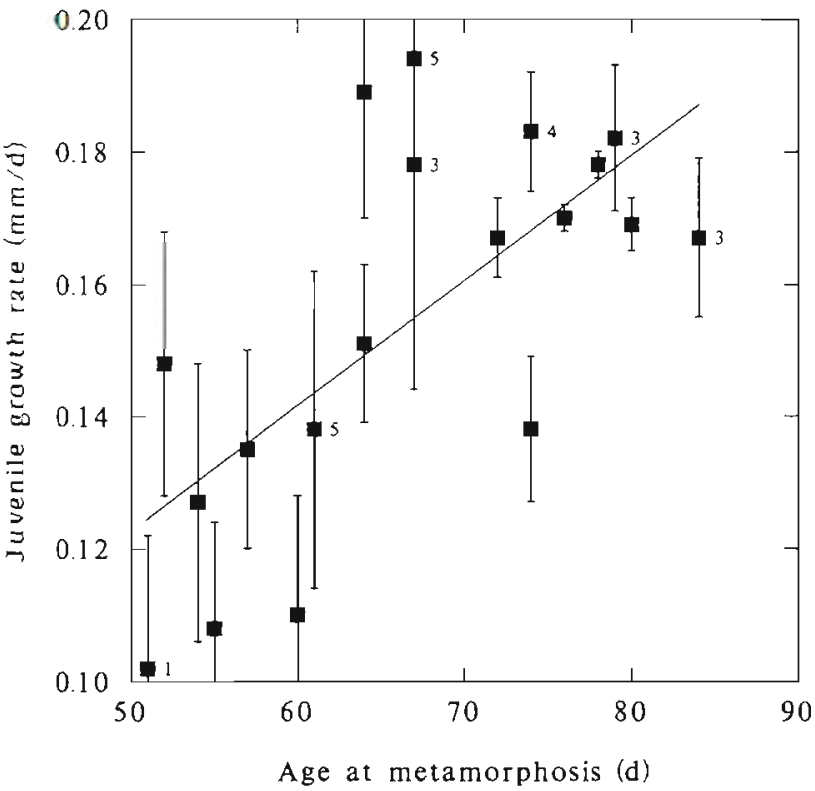

Fig. 1. Pleuronectes americanus. Growth rates $\left(\mathrm{mm} \mathrm{d}^{-1}\right) \mathrm{dur}-$ ing Weeks 1 to 4 of juvenile life for cohorts of fish which metanorphosed at different ages. Each point represents the slope $1=S E$ ) of the regression fitted to weekly averages of standard lengths for fish which metamorphosed on the same day. The fitted line represents a regression through these growth rates $y=0.028+0.002 x, n=19$ ). Numbers to the right of the data points represent the sample sizes for cohorts with fewer than 6 fish

[n both families, fish that metamorphosed late grew more quickly as juveniles than did fish that metamorphosed early (Fig. $1 ; r=0.68$, df $=17, p=0.001$ ). (A quadratic equation did not significantly improve the fit over a linear model to those data.) There was also a statistically significant inverse relationship between larval and juvenile growth rates (Fig. $2 ; \mathrm{r}=-0,68, \mathrm{df}=$ 17. $p=0.002$ ). While the initial density of fish among rearing containers varied ( $n=1$ to 6 ), no effect of density on growth was detected (ANCOVA; $F=0.92, \mathrm{df}=$ $4,13, \mathrm{p}=0.48$ )

The analysis of juvenile growth through Weeks 1 to 7 revealed that weekly growth increments did not differ (Wilks' lambda $=0.74, F=5.013$, df $=5,2, p=0.175$ ). We conclude from this analysis that growth trajectories established during Weeks 1 to 4 of the juvenile period (0.13 $\pm 0.02 \mathrm{~mm} \mathrm{~d}^{-1}, \mathrm{n}=7$ ) were maintained during Weeks 5 to $7\left(0.13 \pm 0.03 \mathrm{~mm} \mathrm{~d}^{-1}, \mathrm{n}=7\right)$. Within these 7 early-metamorphosing cohorts, lengths at equivalent ages determined near the end of the rearing period were not statistically different for the earliest and latest cohorts. The earliest cohort, which metamorphosed at $54 \mathrm{~d}$, averaged $12.63 \mathrm{~mm}(\mathrm{n}=6)$ at Day 103 (Fig. 3, Cohort A): the latest cohort, which metamorphosed at $64 \mathrm{~d}$, averaged $12.68 \mathrm{~mm}$ at Day 106 (Fig. 3, Cohort B). 


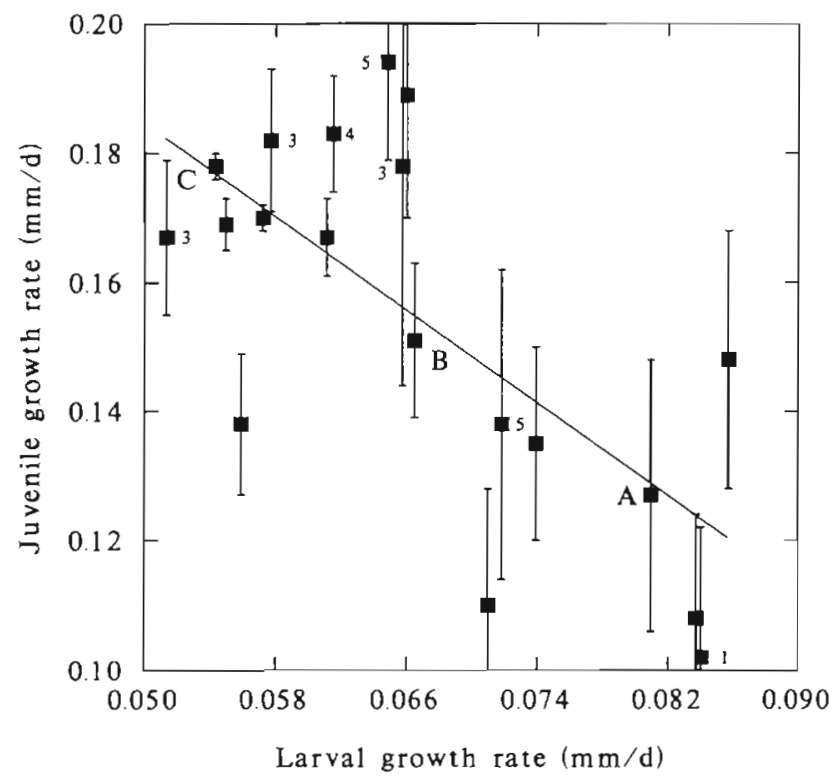

Fig. 2. Pleuronectes americanus. Relationship between larval and juvenile (Weeks 1 to 4 ) growth rates $\left(\mathrm{mm} \mathrm{d}^{-1}\right)$ for cohorts of fish which metamorphosed on the same day $(y=0.275$ $1.803 x, \mathrm{n}=19$ ). Each point represents the slope of the regression fitted to weekly averages of standard lengths for fish which metamorphosed on the same day. Numbers to the left or right of the data points represent sample sizes for cohorts with fewer than 6 fish. Points A, B, and C represent early-, mid-, and late-metamorphosing cohorts $(n=6)$ identified for use in Fig. 3

\section{DISCUSSION}

The results of our experiments indicate that in winter flounder growth rates in the larval and juvenile periods were negatively correlated (Fig. 2). These findings confirm and extend the results obtained by Chambers et al. (1988). Slow larval growth rates were compensated for by faster growth rates as juveniles. As a consequence, size-at-age does not continue to diverge progressively over time (Fig. 3). It is worth noting that this negative covariance between larval and juvenile growth rates is obscured if the analyses of growth rates are pooled and the results are reported as population means, as is commonly done.

We interpret the compensatory growth observed to be an expression of the developmental trajectory of the animals investigated and not an environmental effect. This is because rearing conditions which affect growth, such as temperature, density, food, etc., were constant or were shown to have no statistical influence on growth. Moreover, a 3-fold difference between juvenile and larval growth rates such as we have observed has also been reported for wild starry flounder Platichthys stellatus (Campana 1984).

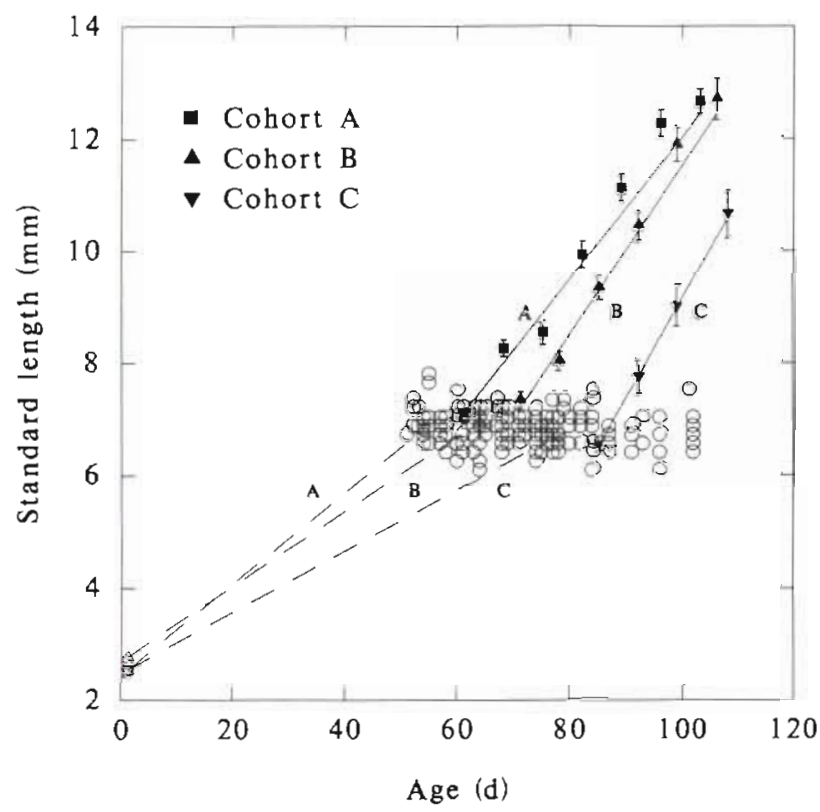

Fig. 3. Pleuronectes americanus. Convergence in juvenile growth trajectories. Three representative growth trajectories (corresponding to cohorts identified in Fig. 2) are shown for the larval and juvenile periods. (O) Our data for length and age at metamorphosis. (- -) Growth rates ( $\mathrm{mm} \mathrm{d}^{-1}$ ) between mean hatching length for fish according to family and mean length at metamorphosis for the 3 cohorts identified in Fig. 2. (-) Estimates of growth rates $\left(\mathrm{mm} \mathrm{d}^{-1}\right.$ ) for the same 3 cohorts during Weeks 1 to 4 of the juvenile period. (Note that the juvenile growth trajectories are offset from the end points of the larval growth trajectories because juvenile growth trajectories begin at Week 1 following metamorphosis.) Estimates of growth rate during Weeks 1 to 4 are projected until Week 7 of the juvenile period for trajectories $A$ and $B$. The weekly mean length-at-age estimates ( $\pm \mathrm{SE}_{1} \mathrm{n}=6$ ) for fish in each of the 3 juvenile cohorts are also shown

\section{Compensatory or targeted growth}

In this discussion we use Atchley's (1984) definition of compensatory growth: '...any growth that reduces the variance in the system or more precisely, when growth in a trait over a given time interval is negatively correlated with the value of that trait at the start of the interval...' Ricker (1975) has briefly discussed growth compensation in adult fish and has reviewed studies which show that, over time, smaller fish tend to catch up with larger adults. Animals from other taxa are also reported to exhibit compensatory or 'targetseeking' growth as they approach sexual maturity (e.g. Monteiro \& Falconer 1966, Atchley 1984). To our knowledge, our findings (coupled with those of Chambers et al. 1988) are the first evidence of compensatory growth between the larval and juvenile periods in fishes, although it has been suggested that compensatory growth in embryos and larvae offset initial egg 
size differences in striped bass Morone saxatalis (Eldridge et al. 1982) and salmon Salmo salar (Hayes \& Armstrong 1942).

The demonstration of compensatory growth between the larval and juvenile periods of winter flounder is important because it implies that size advantages gained during the larval period may be lost as size-at-age converges during the juvenile period. Our findings challenge the notion that size hierarchies (e.g. Brown 1946, 1957, Blaxter 1969, 1988) will be maintained within cohorts of fish. To illustrate the possible implications of our results we have selected 3 cohorts (A, B, C in Fig. 2) which (1) span the entire range of ages at metamorphosis and (2) conform closely to the relationship between larval and juvenile growth rate shown in Fig. 2. The fact that growth rates during Weeks 1 to 4 of the juvenile period were maintained during Weeks 5 to 7 in the 7 cohorts of earlymetamorphosed fish supports the inference that convergence in size-at-age at later points in the juvenile period can occur for cohorts which metamorphose at different ages (see Cohorts $A$ and $B$, Fig. 3). If the juvenile growth rates for cohorts $A$ and $B$ in Fig. 3 were maintained, fish which metamorphosed at $64 \mathrm{~d}$ (Cohort B) could become larger-at-age than those which metamorphosed at $54 \mathrm{~d}$ (Cohort A). Similarly, if linear growth rates are maintained for fish which metamorphose late (e.g. Cohort C, Fig. 3), size-at-age of juveniles in all cohorts will converge or even change in rank order depending on the age at metamorphosis for the cohort. (Note that even if there was no trend in the relationship between larval and juvenile growth rates, this would still indicate that size-at-age does not diverge continuously during the larval and juvenile periods.)

The phenomenon of compensatory growth has been linked to the achievement of target sizes such as the size at sexual maturity (e.g. Monteiro \& Falconer 1966, Atchley 1984). The expression of target sizes in fishes (e.g. Chambers et al. 1988) and other animals (e.g. Atchley 1984) implies that these sizes are linked to key periods during ontogeny when wide variation in body size between individuals could result in strong sizedependent differential mortality or reproductive success. In juvenile winter flounder target sizes may be achieved through compensatory growth.

While the mechanisms leading to the growth rate differences we observed were not investigated in our study, heterogeneity in the growth rates of mice has been linked to heritable traits including the capacity for protein utilization, the rate of food consumption, and the proportion of metabolizable energy for growth (McCarthy 1980). Further, Atchley (1984) has shown that compensatory growth in mice and rats has both substantial genetic and nongenetic components.
In bivalve molluscs individual variation in developmental patterns has also been linked to levels of heterozygosity (e.g. Carlotti \& Nival 1991).

\section{Explanations for compensatory growth}

Size-dependent overwinter mortality could be a selective agent favouring convergent growth in $0+$ winter flounder. Evidence of size-dependent overwinter mortality has been reported for several fish species (e.g. smallmouth bass Micropterus dolomieui, MacLean et al. 1981; smelt Atherina boyeri, Henderson et al. 1988; yellow perch Perca flavescens, Post \& Evans 1989; Atlantic silverside Menidia menidia, Conover \& Ross 1982; white perch Morone americana, Johnson \& Evans 1990). These studies show that overwinter survival is positively correlated to body size at the end of the growing season. Further, these findings imply the existence of a minimum or target size, below which overwinter survival is less probable during long winters. Because winter flounder have a limited growing season (Pearcy 1962), selection should favour fast growth in late-metamorphosing fish in order that they can achieve the minimum target size required for successful overwinter survival. This hypothesis is consistent with the argument of Conover \& Present (1990) that size-dependent overwinter mortality selects for relatively fast growth in Atlantic silverside at high latitudes, where the growing season is short. (Note that other factors such as size-selective predation could conceivably produce the same patterns of growth as we observed.)

Alternatively, compensatory growth may result from differences in the timing of developmental events during the ontogeny of individuals. For example, the tissues and organs of later-metamorphosed fish which have longer larval developmental intervals may have a greater capacity for mature function, and hence facilitate more rapid growth rate relative to individuals that metamorphose early. [Ricklefs (1979a, b) provides evidence for a trade-off between growth rate and the development of mature function in birds.] The relative contribution of size-selective and developmental processes to the dynamics of the growth patterns observed are important foci for future investigation.

\section{Ecological implications of compensatory growth}

Our findings raise doubts as to the generality of the result that size-at-age continues to diverge over time, as reported for larvae (e.g. Rosenberg \& Haugen 1982). Alternatively, our results suggest that, while size-atage diverges during the larval period, it converges 
during the juvenile period, thus contributing to a progressive decline in the size-at-age differences between cohorts. These findings are important because size- and growth-dependent processes are known to directly affect survival [e.g. through their effects on overwinter mortality (e.g. Henderson et al. 1988), predation (e.g. Bailey \& Houde 1989) and starvation (e.g. Miller et al. 1988)]. Size- and growth-dependent processes are also known to interact with the timing and the success of reproduction (see Roff 1992). If the prevailing assumption that growth rate is positively related to survival (e.g. Ware 1975, Chambers \& Leggett 1987, Houde 1987, Rice et al. 1987, Anderson 1988, Beyer 1989, Luecke et al. 1990, Pepin 1990, 1991) is correct, our results suggest that those fish which have the highest mortality risk as larvae (due to the prolonged duration of the larval period) may also have the lowest mortality risk as juveniles. If this covariance in mortality risk exists in situ, a reevaluation of the overall influence of growth rates on survival is in order. Additional research on the growth dynamics of larvae and juveniles, and in particular, on the relationship between growth and mortality rates in these life periods is clearly required to adequately evaluate the survival potential of individuals exhibiting different growth trajectories. Moreover, if the growth compensation we observed between winter flounder larvae and juveniles is general, it will be necessary to conduct examinations of the consequences of size-and growthdependent phenomena throughout the larval and juvenile periods rather than considering growth in those periods in isolation, as has been done in the past.

Acknowledgements. We thank F. Purton and others on the staff of the Huntsman Marine Science Centre (HMSC), St. Andrews, New Brunswick, for their assistance in this work. N Roy and $\mathrm{K}$. Tallon (McGill University) assisted in the laboratory. Additional logistic support was provided by J. D. Neilson (Dept of Fisheries and Oceans, St. Andrews). The constructive comments provided by an anonymous reviewer greatly improved the manuscript. This work was supported by a Natural Sciences and Engineering Research Council (NSERC) postgraduate scholarship to D.F.B. and by NSERC operating and strategic grants to W.C.L. Additional support was provided to D.F.B. by the Anne Vallée Ecological Fund Scholarship and a HMSC Graduate Research Fellowship, and to R.C.C. by the Electrical Power Research Institute's program on Compensatory Mechanisms in Fish Populations.

\section{LITERATURE CITED}

Anderson, J. T (1988). A review of size dependent survival during pre-recruit stages of fishes in relation to recruitment. J. Northw. Atl. Fish. Sci. 8: 55-66

Atchley, W. R. (1984). Ontogeny, timing of development, and genetic variance-covanance structure. Am. Nat. 123: $519-540$

Bailey, K. M., Batty, R. S. (1984). Laboratory study of predation by Aurelia aurita on larvae of cod, flounder, plaice, and herring. development and vulnerability to capture. Mar. Biol. 83: 287-291

Bailey, K. M., Houde, E. D. (1989). Predation on eggs and larvae of marine fishes and the recruitment problem. Adv. mar. Biol. 25: 1-83

Beyer, J. (1989). Recruitment stability and survival: simple size-specific theory with examples from the early life dynamics of marine fish. Dana 7: 45-147

Blaxter, J. H. S. (1969). Development of eggs and larvae. In: Hoar, W. S., Randall, D. J. (eds.) Fish physiology, Vol. 3, Reproduction and growth, bioluminescence, pigments, and poisons. Academic Press, New York, p. 177-252

Blaxter, J. H. S. (1988). Pattern and variety in development In: Hoar, W. S., Randall, D. J. (eds.) Fish physiology, Vol $11 \mathrm{a}$. The physiology of developing fish: eggs and larvae. Academic Press, New York, p. 1-58

Brown. M. E. (1946). The growth of brown trout (Salmo trutta Linn .) 1. Factors influencing the growth of trout fry. J. exp. Biol. 22: 118-129

Brown, M. E. (1957). Experimental studies on growth. In: Brown, M. E. (ed.) The physiology of fish, Vol. 1. Academic Press, New York, p. 371-400

Brownell, C. L. (1985). Laboratory analysis of cannibalism by the larvae of the cape anchovy Engraulus capensis. Trans. Am. Fish. Soc. 114:14-25

Campana, S. E. (1984). Microstructural growth patterns in the otoliths of larval and juvenile starry flounder, Platichthys stellatus. Can. J. Zool. 62: 1507-1152

Carlotti, F., Nival, S. (1991). Individual variability of development in laboratory-reared Temora stylifers copepodites: consequences for the population dynamics and interpretation in the scope of growth and development rules. $J$ Plankton Res. 13: 801-813

Chambers, R. C., Leggett, W. C. (1987). Size and age at metamorphosis in marine fishes: an analysis of laboratoryreared winter flounder (Pseudopleuronectes americanus) with a review of variation in other species. Can. J. Fish. Aquat. Sci. 44: 1936-1947

Chambers, R. C., Leggett, W. C., Brown, J. A. (1988). Variation in and among early life history traits of laboratoryreared winter flounder Pseudopleuronectes americanus. Mar. Ecol. Prog. Ser. 47: 1-15

Conover, D. O., Present, T M. C. (1990). Countergradient variation in growth rate: compensation for length of the growing season among Atlantic silversides from different latitudes. Oecologia 83: 316-324

Conover, D. O., Ross, M. R. (1982). Patterns in seasonal abundance, growth, and biomass of the Atlantic silverside, Menidia menidia, in New England estuary. Estuaries 5: $275-286$

Eldridge, M. B., Whipple, J. A., Bowers, M. J. (1982). Bioenergetics of growth of striped bass, Morone saxatllis, embryos and larvae. Fish. Bull. U.S. 80: 461-474

Folkvord, A., Hunter, J. R. (1986). Size-specific vulnerability of northern anchovy, Engraulis mordax, larvae to predation by fishes. Fish. Bull. U.S. 84: 859-869

Fuiman, L. A. (1989). Vulnerability of Atlantic herring larvae to predation by yearling herring. Mar. Ecol. Prog. Ser. 51. 291-299

Hayes, F. R., Armstrong, F. H. (1942). Physical changes in the constituent parts of developing salmon eggs. Can. J. Res. 20: $99-114$

Henderson, P. A., Holmes, R. H. A., Bamber, R. N (1988). Size-selective overwintering mortality in the sand smelt, Atherina boyeri Risso, and its role in population regulation. J. Fish Biol. 33: 221-223

Houde, E. D. (1987). Fish early life dynamics and recruitment 
variability. Am. Fish. Soc. Symp. 2: 17-29

Johnson, T B., Evans, D. O. (1990). Size-dependent winter mortality of young-of-the-year white perch: climate warming and invasion of the Laurentian Great Lakes. Trans. Am. Fish. Soc. 119: 301-313

Litvak, M. K., Leggett, W. C. (1992). Age and size-selective predation on larval fishes: the bigger-is-better hypothesis revisited. Mar. Ecol. Prog. Ser. 81 13-24

Luecke, C., Rice. J. A., Crowder, L. B., Yeo, S. F., Bınkowski, F. P. (1990). Recruitment mechanisms of bloater in Lake Michigan: an analysis of the predatory gauntlet. Can. J. Fish. Aquat. Sci. 47:524-532

MacLean, J. A., Shuter, B. J., Regier, H. A., MacLeod, J. C. (1981). Temperature and year-class strength of smallmouth bass. Rapp. P.-v. Réun. Cons. int. Explor. Mer 178: $30-40$

McCarthy, J C. (1980). Morphological and physiological effects of selection for growth rate in mice. In: Robertson, A. (ed.) Selection experiments in laboratory and domestic animals. Commonwealth Agricultural Bureau, Slough, p. $100-109$

Miller, $\Upsilon$ J., Crowder, L. B., Rice, J. A., Marschall, E. A. (1988). Larval size and recruitment mechanisms in fishes: towards a conceptual framework. Can. J. Fish. Aquat. Sci. 45: $1657-1670$

Monteiro, L. S., Falconer, D. S. (1966). Compensatory growth and sexual maturity in mice. Anim. Prod. 8: 179-192

Morrison, D. F. R. (1976). Multivariate statistical methods. McGraw-Hill, New York

Pearcy, W. G. (1962). Ecology of an estuarine population of winter flounder Pseudopleuronectes americanus (Walbaum). III. Distribution, abundance, growth, and production of juveniles; survival of larvae and juveniles. Bull. Bingham oceanogr. Coll. 18: 39-64

Pepin, P. (1990). Predation and starvation of larval fish: a numerical experiment of size- and growth-dependent survival. Biol. Oceanogr. 6: 23-44

Pepin, P. (1991). The effect of temperature and size on development and mortality rates of pelagic life history stages of marine fish. Can. J. Fish. Aquat. Sci. 48: 503-518

Pepin, P., Pearre, S. Jr, Koslow, J. A. (1987). Predation on larval fish by Atlantic mackerel, Scomber scombrus, with a comparison of predation by zooplankton. Can. J. Fish. Aquat. Sci. 44: 2012-2018

This article was submitted to the editor
Pepin, P., Shears, T. H., de Lafontaine, Y (1992). Significance of body size to the interaction between a larval fish (Mallotus villosus) and a vertebrate predator (Gasterosteus aculeatus). Mar. Ecol. Prog. Ser. 81: 1-12

Post, J. R., Evans, D. O. (1989). Size-dependent overwinter mortality of young-of-the-year yellow perch (Perca flavescens): laboratory, in situ enclosures, and field experiments. Can. J. Fish. Aquat. Sci. 46: 1958-1968

Rice, J. A., Crowder, L. B., Holey, M. E. (1987). Exploration of mechanisms regulating larval survival in Lake Michigan bloater: a recruitment analysis based on characteristics of individual larvae. Trans. Am. Fish. Soc. 116: 703-718

Ricker, W. E. (1975). Computation and interpretation of biological statistics of fish populations. Bulletin 191, Dept of Fisheries and Oceans, Ottawa

Ricklefs, R. E. (1979a). Adaptation, constraint, and compromise in avian postnatal development. Biol. Rev. Cambridge Philos. Soc. 54:269-290

Ricklefs, R. E. (1979b). Patterns of growth in birds. V. A comparative study of development in the starling, common tern and Japanese quail. Auk 96: 10-30

Roff, D. A. (1992). The evolution of life histories; theory and analysis. Chapman and Hall, New York

Rosenberg, A. A., Haugen, A. S. (1982). Individual growth and size-selective mortality of larval turbot (Scopthalmus maximus) reared in enclosures. Mar. Biol. 72: 73-77

Seikai, T., Tanangonan, J. B., Tanaka, M. (1986). Tempera. ture influence on larval growth and metamorphosis of the Japanese flounder Paralichthys olivaceus in the laboratory. Bull. Jap. Soc. scient. Fish. 52: 977-982

Semlitsch, R. D., Scott, D. E., Pechmann, J. H. K. (1988). Time and size at metamorphosis related to adult fitness in Ambystoma talpoideum. Ecology 69: 184-192

Smith, D. C. (1987). Adult recruitment in chorus frogs: effects of size and date at metamorphosis. Ecology 68: 344-350

Travis, J., Emerson, S., Blouin, M. (1987). A quantitativegenetic analysis of larval life-history traits in Hyla crucifer Evolution 41.145-156

Ware, D. M. (1975). Relation between egg size, growth and natural mortality of larval fish. J. Fish. Res. Bd Can. 32 2503-2515

Wilkinson, L. 1990. SYSTAT the system for statistics. SYSTAT, Inc., Evanston, IL

Manuscript first received: June 23, 1992

Revised version accepted: April 14, 1993 